IFAC Report

\title{
Work of the Social Effects of Automation Committee from Bad Boll to Enschede
}

\section{R. M. J. WITHERS* and J. E. RIJNSDORP†}

Key Word Index - Social and behavioural science; man-machine systems; robots; manufacturing processes; job design; group technology.

\begin{abstract}
Summary-The paper summarises the activities of the IFAC Committee on Social Effects of Automation during the period 1974-1977. A Workshop was held about 'Productivity and Man' at Bad Boll (F.R.G.) in January 1974. A number of Newsletters were published. Factory visits were made to a Steel Rolling Mill, an Automobile Plant, an Electro-Mechanical and an Electronic Assembly plant. Contributions were made to the IFAC Congress at Boston (August 1975), and will be offered to the Congress at Helsinki (June 1978). Preparations are being made for a Workshop on Case Studies in Automation, related to Humanization of Work, to be held at Enschede Netherlands in November 1977.
\end{abstract}

Introduction

THE International Federation of Automatic Control was founded during an International Conference at Heidelberg (1956). It is supported by National Member Organizations from all continents.

Every three years a general congress held, where all fields and aspects of control are included. The interpretation of the term 'control' has gradually become broader; it now encompasses the interactions with planning, operations research, world dynamics, the environment, economics, computer science, and human factors.

IFAC also has a number of technical committees, which are responsible for planning and coordinating activities in certain fields, such as control theory, education, applications, manufacturing technology, systems engineering, management science. In 1971 a Committee was formed to deal with Social Effects of Automation. The decision was made to direct the attention primarily on a specific area : the interactions between automation techniques and conditions in industry.

More specifically the aims were to make all control engineers aware of social effects of their work, to involve a smaller group of interested people in a more thorough analysis of social effects, and to provide information about new developments

Workshop about 'Productivity and Man'

The first major event sponsored by the committee was the Workshop in Bad Boll (F.R.G.) in January 1974. The proposal for such a Workshop was made at the Paris conference of IFAC in June 1972, during a round table discussion.

The workshop has been fully described by Peter Schuh and Phil Sprague in an official publication 'Productivity and Man'. It had the following main characteristics:

provision of ideal facilities in the Evangelische Acadamie at Bad Boll

attendance by forty-three men and women from twelve countries

representatives from trades unions, behavioural science, engineering and management

presentation and discussion of nineteen pre-printed case studies in four sequential work sessions

an introductory session to set the main topics and a closing session to produce a concluding statement

publication of the Workshop proceedings.

The Concluding Statement of the Workshop reads as follows:

*Urwick Technology Management, London, England.

$\uparrow$ Twente University, Enschede, The Netherlands
"Based on (a) the case studies submitted from thirteen countries documenting the application of automation and technology to a variety of industrial and institutional problems and (b) the three days of discussions by our group of more than forty participants representing a wide range of educational and professional disciplines, we make the following observations

1. The case studies submitted indicate that great gains in productivity have been achieved through the application of automation to human activities; these gains have not only been realized in terms of greater output, increased wages and improved product quality but also in extended leisure time, improved health and better living conditions.

2. The case studies submitted reveal that in many cases too little consideration was given to human factors of work in the design of the automation systems.

3. The Workshop participants concluded that the human shortcomings mentioned in point 2 above were a result of (a) insufficient recognition of the opportunities inherent in new technology to overcome these ill effects and (b) inadequate recognition of the increased awareness of people regarding the dehumanization of work which can result from the application of automation.

4. The Workshop participants believe that man/machine relationships can and should be optimized and that, therein, lies the greatest opportunity and challenge for the control engineer.

5. The workshop participants believe that, too frequently, the control engineer is brought into the design planning process too late to make an optimum contribution; further, that there has been insufficient dialogue and co-operation between control engineers and social scientists due primarily to their respective ignorance of each other's discipline and education.

Recognizing our primary responsibility to the International Federation of Automatic Control and the control engineers and scientists throughout the world which make up its membership, we make the following Recommendations to Control Engineers:

1. In designing automation systems, the Control Engineer should consult with and encourage the active participation of all people who are or will be involved in the system.

2. In designing automation systems, the Control Engineer should not restrict the amount of information about the system: on the contrary, he should provide all people involved in the system with as much information as possible.

3. In designing automation systems, the Control Engineer should consult and co-operate with suitably qualified social scientists and trade union representatives in order to produce more effective systems from a human standpoint.

4. In designing automation systems, the Control Engineer should be encouraged to take advantage of the unique capabilities of man, to enrich man's role in the system. An important objective of the system should be greater humanization and opportunity for human self-actualization and growth.

5. The Control Engineer should give serious consideration to reorienting or reshaping his profession and its educational base to include exposure to economic, social and psychological factors; failure to incorporate such aspects in his thinking and activity will severely limit the effectiveness of his designs." 
At a subsequent committee it was agreed to follow up the Workshop by in-depth investigations by the Committee at a number of factory locations. It was also agreed to propagate the work of the Committee by means of a Newsletter. It was further decided to make preparations for the August 1975 IFAC Congress at Boston, U.S.A. and it was agreed to arrange another Workshop. At this time the Chairmanship of our Committee passed from Phil Sprague to Fred Margulies.

\section{Nensiletteris}

As this report is being written, the Committee's third newsletter is due and plans exist for editing the fourth and fifth newsletters

The procedure is that responsibility for each newsletter rests with a named individual, as follows
No. 1 H. Rosenbrock
No. 2. J. Dockstade
No. 3 A. B. Aunc
No. 4 P. Schuh
No. 5 . S. Aida

The master copies are sent to a number of conninl1tee members for duplication and distribution on an area bask Mistribution is undertaken by the following:

$\begin{array}{ll}\text { N. \& S. America } & \text { J. Dockstilder } \\ \text { U.K. \& TC 9 } & \text { H. Rosenbrock } \\ \text { West Germany } & \text { P. Schuh } \\ \text { France \& Switzerland } & \text { F. Muller } \\ \text { Austria } & \text { F. Marquilies } \\ \text { Scandinavia } & \text { A. B. Aune } \\ \text { Socialist Countries } & \text { N. S. Rajbman }\end{array}$

The committee's Newsletters aim to provide:

preview of forthcoming events

reports on conferences, workshops, meetings etc. reviews of books and papers

vutstanding papers in full

reports on research

suggestions for committee work

The first Newsletter was issued in March 1976 and the second in November 1976. The third Newsletter is due in April 1977. It is primarily aimed at meeting the needs of committee members and their friends and an initial circulation of around 100 copies was envisaged. In practice many more copies than this have been circulated.

Reciprocal arrangements regarding the circulation of $\mathrm{New}$ Newsletters have been made with Council on Quality of Working Life through the Chairman, Professor A. T. M. Wilson.

Similar arrangements for exchange of Newsletters have been made with the IFIP committee TC 9 devoted to the study of relationships between computer technology and society.

\section{Factory risits}

At the Bad Boll Workshop, proceedings fell under three main headings:

\section{process industrics \\ manufacturing industries \\ office work}

The initial factory visit was particularly relevant to the first of these. The "Hoogovens" plant at ljmuiden in the Netherlands is one of the most up-to-date steel works in Europe with a high level of automation throughout. It has two hot strip mills, one of which is equipped with a comprehensive computer control system. At the time of the Committee's visit (February 1976) the system had been in operation for some years and there had just been concluded an eighteen month study into Human Factors by a cooperative team from Hoogovens staff, the University of Delft, and the British Steel Corporation. The study had been financed with assistance by the European Coal and Steel Community. The meeting was attended by fourteen committee members who spent two days visiting and discussing the plant together with senior staff from Hoogovens and the co-operative study team.

Participants expressed their appreciation of the character of the meeting and it was agreed to repeat the structure in future.
Fuli reports of the meeting appeared in Newsletter No. 1. A main impression for the meeting was the considerable attempt being made to bring together working experiences of operators. behavioural scientists, engineers and managers in an attempt to make improvements for the future. Another was the organisation which exhibits a very high standard of plant technology and which attempts to involve its work force in an open exchange of information. Thirdly. it was interesting to see the attempt of maintaining good visual and physical proximity to the process, with the control room used as a meeting place and management centre.

It had been hoped to compare conditions in the highly attomated hot strip mill No. 2 with those in the less advanced mill No. 1. This proved impracticable for a number of reasons. Whilst there was a cost benefit to Hoogoven in terms of improved heat economy and production quality there were no labour sivings; in fact twelve relatively unskilled people were replaced by a need for an equivalent number given with higher levels of skill and operator training in a lengthy process.

Our second factory visit was the Olivetti's main works at Ivrea in Northern Italy. Olivetti face particularly challenging problems because of the change in their technology base from electromechanical 'fein werk technik' to electronics.

At the time of this visit the committee comprised forty-two members from seventeen countries and thirteen members were in attendance from ten countries. Two days were spent on the visit to Olivetli and two further half-days were spent discussing committee busines

Olivetti have made signilicant progress in two directions in response to the difficulties human beings face when coupled 10 mechanical flow lines and asked to work repetitively on short cycle times. Firstly they have been introducing production systems based on group technology since 1963. In 1976. 2.000 people were so organised at Ivrea. Secondly, since 1972 they have been introducing robots: in 1976 they had twenty at work. equivalent in speed to some sixty men, and able to work more or less continuously.

There were intensive discussions during our visit both about Group Technology and about Robots. There is a full report on our visit in Newsletter No. 3. Among many impressions of our visit was the big investments being made by Olivetti both in its people by means of training schemes and in its technology. The effects on the structure of work and upon the management structure were considerable with much evidence of matrix and project management systems.

\section{Lisit to Daimler-Benz, Sindelfingen (F.R.G.)}

In May 1977. a visit was paid to the Daimler-Benz plant at Sindelfingen, where Mercedes cars are being assembled. About 10 committee members particpated.

The daily production is about 1500 cars, of which are sold to employees for a reduced price. The total working force is 34,000 , including 10,000 guest-labourers.

Job enlargement has been introduced in order to improve the cycle time in some monotonous jobs; for instance a worker will take every fourth car and spent $4 \times 2$ minutes on it. Still there are several people strongly tied to the pace of the machine, amongst others in the pressing of body parts and in the painting shops. The creation of more favourable working conditions tends to enlarge intermediate buffers and to decrease productivity.

Many robots are being used, mainly for spot welding and painting. However, locations which are difficult to reach remain to be done by human beings.

Visit to Hewlett-Packard, Boblingen (F.R.G.)

Also in May 1977, a visit was paid to the Hewlett-Packard plant at Boblingen. Of the total working force of 1100,380 are employed in production. Small series of a great variety of electronic instruments are being manufactured.

The interior of the buildings has been arranged in open style, where even the department head's desk can be seen by everybody.

The organisation is based on the principle of 'management by objectives'. Every year objectives are formulated by the Supervisor under negotiation with the person concerned. The latter works independently, with a semi-annual inspection by the supervisor. On the lowest level however, there are difficulties in 
defining feasible objectives. Special attention should be paid to the training of foremen in applying the principle on their level

Job enlargement has been realised in the assembly of printed circuits boards. The testing of these boards will be done by computer, which enables job upgrading for quality inspectors to programming, or to customer servicing.

General impressions from the factory visits

There is a variety of reasons for starting projects on humanisation of work, such as: High absenteeism and turn-over, higher levels of education of young employees, changes in technology accompanied by changes in jobs, pressures from trade unions, new legislation, and/or initiatives by management. In any case, such projects only have a chance of success if they are supported by management.

An important condition imposed upon management, particularly under the present economic conditions, is to keep production efficiency at least on the same level. Additional costs of humanisation of work must therefore be compensated by some form of productivity improvement. Giving more individual responsibility for product quality, or better information to the operators about process performance can help secure this end.

Great attention should be paid to training, not only of the workers concerned, but also of their supervisors. In advanced automation projects, the operators should understand the decisions taken by the computer.

Modern computer and communication technology can enable the worker to take actions which traditionally are the realm of the supervisory level. This, inevitably, must lead to changes in the organisation structure.

The present generation of industrial robots have several limitations, hence a certain number of monotonous tasks still have to be allocated to human beings.

\section{IF $A C$ congress}

The International Programme Committee of the IFAC Congress 1975, which was held at Boston (U.S.A.). agreed to include a specially commissioned paper among its list of plenary sessions. In fact a poll put the Social Effects of Automation fourth on a list of sixteen titles for choice.

This paper was a joint effort by K. Bibby, F. Margulies, J. Rijnsdorp and J. Withers, and presented by J. Rijnsdorp. In addition, two special interest sessions were organised comprising twelve papers which stimulated great interest and lively discussion. A well-attended round table meeting under the chairmanship of Dr. Ellis-Scott provided further suggestions concerning the future activities of the committee.

For the coming IFAC Congress, which will be held in Helsinki, June 1978, the following survey papers have been proposed:
Technological change, productivity and employment, by $\mathrm{Mr}$. Cooley and $\mathbf{J}$. Withers;

Co-operation between control engineers, social scientists and users in automation system design, by Aune, M. Cooley and $\mathbf{J}$. Rijnsdorp.

Further, round table discussions will be held about these two subjects, and a third one will be devoted to Man-Machine Interfaces for Process Control in cooperation with Technical Committee 6 of 'Purdue Europe".

Finally, two technical sessions are envisaged about Social Effects of Automation in the Printing Industry, to be organised by Kavonius and Withers; and about Automation in Offices, to be organised by Bjorn-Andersen.

Workshops at Enschede

(Netherlinds)

This paper is intended for presentation and discussion at the Workshop about Case Studies in Automation, related to Humanization of work, to be held at Enschede (Netherlands) from 31st October to 4th November, 1977.

A provisional programme was agreed to give three working sessions or case studies, with two sessions devoted to a summary and recommendations, and hopefully a technical visit to Philips.

The workshop is being organised by a local committee led by Professor J. Rijnsdorp

\section{Future work}

The committee meets very infrequently and its membership is spread across many countries and is composed of individuals with heavy commitments.

I1 has therefore been necessary to concentrate on a relatively narrow front but with a strong theme in order to achieve success.

From the foregoing it will be appreciated that the Committee's past activities have focussed particularly on the problems of humanising work in manufacturing situations with special reference to automation. It is felt that this concentration has yielded good results.

Our factory visits, newsletters, workshop programme, and congress contributions have all yielded favourable comment and enabled many to benefit for the sharing of working experience.

Whilst however the committee feels that the selection of the manufacturing sector is justified by the wealth it so necessarily creates for society to spend, it has to acknowledge that there is an increasing employment opportunity in the service sector and that other aspects and activities such as medical aid, transport and communications all deserve study. The possible scope of the Committee's activities is therefore very wide and it is planned to hold discussions at Twente to see what more might be fruitfully explored in the future. 